\title{
Solid $\mathrm{CO}_{2}$ in low-mass young stellar objects Comparison between Spitzer and laboratory spectra
}

\author{
S. Ioppolo ${ }^{1, \star}$, I. Sangiorgio ${ }^{2,3}$, G. A. Baratta ${ }^{3}$, and M. E. Palumbo ${ }^{3}$ \\ 1 Raymond \& Beverly Sackler Laboratory for Astrophysics, Leiden Observatory, Leiden University, PO Box 9513, 2300 RA Leiden, \\ The Netherlands \\ 2 Dipartimento di Fisica e Astronomia, Università degli Studi di Catania, via Santa Sofia 64, 95123 Catania, Italy \\ 3 INAF - Osservatorio Astrofisico di Catania, via Santa Sofia 78, 95123 Catania, Italy \\ e-mail: mepalumbo@oact.inaf.it
}

Received 28 January 2013 / Accepted 6 March 2013

\begin{abstract}
Context. Solid interstellar $\mathrm{CO}_{2}$ is an abundant component of ice dust mantles. Its ubiquity towards quiescent molecular clouds, as well as protostellar envelopes, has recently been confirmed by the IRS (InfraRed Spectrograph) aboard the Spitzer Space Telescope. Although it has been shown that $\mathrm{CO}_{2}$ cannot be efficiently formed in the gas phase, the $\mathrm{CO}_{2}$ surface formation pathway is still unclear. To date several $\mathrm{CO}_{2}$ surface formation mechanisms induced by energetic (e.g., UV photolysis and cosmic ray irradiation) and nonenergetic (e.g., cold atom addition) input have been proposed.

Aims. Our aim is to investigate the contribution of cosmic ray irradiation to the formation of $\mathrm{CO}_{2}$ in different regions of the interstellar medium (ISM). To achieve this goal we compared quantitatively laboratory data with the $\mathrm{CO}_{2}$ bending mode band profile observed towards several young stellar objects (YSOs) and a field star by the Spitzer Space Telescope.

Methods. All the experiments presented here were performed at the Laboratory for Experimental Astrophysics in Catania (Italy). The interstellar relevant samples were all irradiated with fast ions (30-200 keV) and subsequently annealed in a stainless steel high vacuum chamber $\left(P<10^{-7}\right.$ mbar). Chemical and structural modifications of the ice samples were monitored by means of infrared spectroscopy. Laboratory spectra were then used to fit some thirty observational spectra.

Results. A qualitative analysis shows that a good fit can be obtained with a minimum of two components. The choice of the laboratory components is based on the chemical-physical condition of each source. A quantitative analysis of the sources with known visual extinction $\left(A_{V}\right)$ and methanol abundances highlights that the solid carbon dioxide can be efficiently and abundantly formed after ion irradiation of interstellar ices in all the selected YSOs in a time compatible with cloud lifetimes $\left(3 \times 10^{7}\right.$ years). Only in the case of field stars can the expected $\mathrm{CO}_{2}$ column density formed upon energetic input not explain the observed abundances. This result, to be confirmed along the line of sight to different quiescent clouds, gives an indirect indication that $\mathrm{CO}_{2}$ can also be formed in an early cloud stage through surface reactions induced by non-energetic mechanisms. In a later stage, when ices are exposed to higher UV and cosmic ray doses, the $\mathrm{CO}_{2}$ total abundance is strongly affected by energetic formation mechanisms.

Conclusions. Our results indicate that energetic processing of icy grain mantles significantly contribute to the formation of solid phase interstellar $\mathrm{CO}_{2}$.
\end{abstract}

Key words. astrochemistry - molecular processes - methods: laboratory - techniques: spectroscopic - ISM: abundances ISM: molecules

\section{Introduction}

Interstellar solid $\mathrm{CO}_{2}$ was first identified towards several protostars by the InfraRed Astronomical Satellite (IRAS) in the late 80s (d'Hendecourt \& Jourdain de Muizon 1989). Since its detection, solid $\mathrm{CO}_{2}$ has been observed abundant $(\sim 10-30 \%$ with respect to $\mathrm{H}_{2} \mathrm{O}$ ice) towards different environments, such as quiescent dark clouds and star forming regions by the Infrared Space Observatory (ISO; e.g., Gerakines et al. 1999; Gibb et al. 2004; Nummelin et al. 2001) and more recently by the Spitzer Space Telescope (e.g., Boogert et al. 2004; Pontoppidan et al. 2005, 2008; Whittet et al. 2007; Öberg et al. 2008; Zasowski et al. 2009; Bottinelli et al. 2010; Cook et al. 2011). These observations have established that solid $\mathrm{CO}_{2}$, together with $\mathrm{H}_{2} \mathrm{O}, \mathrm{CO}$,

\footnotetext{
* Present address: California Institute of Technology, Division of Geological and Planetary Sciences, 1200 E. California Blvd, Pasadena, 91125 California, USA.
}

and in some cases $\mathrm{CH}_{3} \mathrm{OH}, \mathrm{NH}_{3}$, and $\mathrm{CH}_{4}$, represents the bulk of solid-state species in the interstellar and circumstellar medium (ISM/CSM) (e.g., Allamandola et al. 1992; Gibb et al. 2004; Öberg et al. 2011). In the past decades, several experimental studies have focused on the profile of the IR absorption bands of solid $\mathrm{CO}_{2}$ in different astrophysical relevant mixtures as a function of temperature and investigated the interaction of $\mathrm{CO}_{2}$ with neighbor molecules, such as $\mathrm{H}_{2} \mathrm{O}$ and $\mathrm{CH}_{3} \mathrm{OH}$ (e.g., Sandford \& Allamandola 1990; Hudgins et al. 1993; Ehrenfreund et al. 1997, 1999; Dartois et al. 1999; Palumbo \& Baratta 2000; Baragiola 2003; Gálvez et al. 2007, 2008; White et al. 2009). Recently, Pontoppidan et al. (2008) have compared selected laboratory spectra to Spitzer observations towards star forming regions, and found that roughly two thirds of the solid $\mathrm{CO}_{2}$ observed in quiescent molecular clouds and star forming regions is embedded in water-rich environment, suggesting that the formation routes of these two molecules are linked. The 
remaining $\mathrm{CO}_{2}$ ice is predominantly found in an $\mathrm{H}_{2} \mathrm{O}$-poor, $\mathrm{CO}$-rich environment.

Despite its ubiquity and abundance, the formation of interstellar $\mathrm{CO}_{2}$ ice remains uncertain. It is widely accepted that $\mathrm{CO}_{2}$ is not efficiently formed in the gas phase, with subsequent accretion onto interstellar grains $\left(\mathrm{CO}_{2}^{\text {gas }} / \mathrm{CO}_{2}^{\text {ice }} \ll 1\right.$; van Dishoeck et al. 1996; Boonman et al. 2003). Therefore, the observed $\mathrm{CO}_{2}$ most likely has to be formed in the solid phase through surface reactions with or without energetic input (e.g., UV photons with $6.9 \leq E \leq 13.6 \mathrm{eV}$, and cosmic rays with $E \sim \mathrm{MeV}$ ). The problem is then further complicated by the fact that several reaction mechanisms have been proposed with often uncertain efficiency in the solid phase. The most cited surface reaction routes are

$\mathrm{CO}+\mathrm{O} \rightarrow \mathrm{CO}_{2}$

$\mathrm{HCO}+\mathrm{O} \rightarrow \mathrm{CO}_{2}+\mathrm{H}$

$\mathrm{CO}+\mathrm{OH} \rightarrow \mathrm{CO}_{2}+\mathrm{H}$.

The most straightforward surface reaction channel is the addition of an O atom to solid CO ice (Tielens \& Hagen 1982). However, reaction 1 has a high reaction barrier (2970 K in the gas phase; Talbi et al. 2006; Grim \& d'Hendecourt 1986), because the $\mathrm{CO}\left({ }^{1} \Sigma\right)+\mathrm{O}\left({ }^{3} \mathrm{P}\right)$ reactants do not correlate directly with the singlet ground state $\mathrm{CO}_{2}\left({ }^{1} \Sigma\right)$. Ruffle \& Herbst (2001) were only able to reproduce the $\mathrm{CO}_{2}$ abundances observed towards cold clouds (e.g., Elias 16) if they artificially lowered the barrier to $130 \mathrm{~K}$ in their astrochemical model. Recently, Goumans \& Andersson (2010) used harmonic quantum transition state theory to prove that, while quantum mechanical tunneling through the activation barrier increases the classical reaction rate for reaction 1 at low temperatures $(10-20 \mathrm{~K})$, the onset of tunneling is at temperatures that are too low for the reaction to efficiently contribute to $\mathrm{CO}_{2}$ formation in quiescent cold regions. Reaction 1 has been experimentally investigated by temperatureprogramed desorption experiments using thermal $\mathrm{O}$ atoms below $160 \mathrm{~K}$ (Roser et al. 2001) and by energetic O atoms (Madzunkov et al. 2006). In the first case, reaction 1 was found to proceed only in water pores under a water ice cap and upon heating, while in the second case the energetic $\mathrm{O}$ atoms allowed the reaction to proceed. More recently, Raut \& Baragiola (2011) have shown by means of infrared (IR) spectroscopy and microgravimetry that $\mathrm{CO}_{2}$ forms in small quantities during codeposition of $\mathrm{CO}$ and cold (non-energetic) $\mathrm{O}$ and $\mathrm{O}_{2}$ into thin films at $20 \mathrm{~K}$. They find that $\mathrm{O}$ atoms primarily react with $\mathrm{O}$ to form $\mathrm{O}_{2}$ and with $\mathrm{O}_{2}$ to form $\mathrm{O}_{3}$. Therefore, reaction 1 is most likely not an efficient surface $\mathrm{CO}_{2}$-formation route unless energetic processing is involved.

It has been further suggested that solid $\mathrm{CO}_{2}$ is formed through surface reaction 2 (Ruffle \& Herbst 2001), which has never been experimentally investigated in the solid phase. Alternatively, solid $\mathrm{CO}_{2}$ can be formed through reaction 3 , which yields an $\mathrm{HO}-\mathrm{CO}$ intermediate. This complex can directly dissociate, forming solid $\mathrm{CO}_{2}$ and leaving an $\mathrm{H}$ atom, or can be stabilized by intramolecular energy transfer to the ice surface and eventually react with an incoming $\mathrm{H}$ atom in a barrierless manner to form $\mathrm{CO}_{2}$ and $\mathrm{H}_{2}$ or other products with a purely statistical branching ratio (Goumans et al. 2008). Recently, several independent experimental studies have shown that reaction 3 is an efficient surface $\mathrm{CO}_{2}$ formation channel without energetic input (i.e., Oba et al. 2010; Ioppolo et al. 2011; Noble et al. 2011). Moreover, reaction 3 can explain the observed formation link between $\mathrm{CO}_{2}$ and $\mathrm{H}_{2} \mathrm{O}$ ice under interstellar conditions, since $\mathrm{OH}$ radicals are involved in the reaction scheme, and water can be efficiently formed through reactions $\mathrm{OH}+\mathrm{H}$ and $\mathrm{OH}+\mathrm{H}_{2}$ (e.g., Romanzin et al. 2011; Oba et al. 2012). This is also recently confirmed by Garrod \& Pauly (2011) in their three-phase (gas/surface/mantle) astrochemical model in which formation of solid $\mathrm{CO}_{2}$, as well as other species, is investigated. Thus, a combination of observations, models, and laboratory experiments indicates that $\mathrm{CO}_{2}$ can be formed through non-energetic induced surface reactions in a polar environment already in a quiescent molecular cloud phase.

Although dense molecular clouds are shielded from UV radiation to a great extent by dust particles, cosmic rays can still penetrate these regions and, therefore, they can efficiently process the ices (e.g., Prasad \& Tarafdar 1983; Jenniskens et al. 1993; Mennella et al. 2003). Energetic processing becomes even more important at later stages of star forming regions, when ices are exposed to the irradiation of a new born star. In dense molecular clouds, cosmic rays generate UV photons and fast ions that can indeed release their energy to the target material. Owing to the interaction with fast ions molecular bonds are broken and, on timescales of picoseconds, the molecular fragments recombine giving rise to a rearrangement of the chemical structure that leads to forming new molecular species. In the case of UV photolysis, the energy is released to the target material through a single photo-dissociation or photo-excitation event. Therefore, energetic processing most likely contribute to the total $\mathrm{CO}_{2}$ abundance observed in polar and apolar interstellar ices. For instance, (i) photo-dissociation of $\mathrm{H}_{2} \mathrm{O}$ ice is a possible mechanism to form available $\mathrm{OH}$ radicals that can subsequently react with $\mathrm{CO}$ molecules to form solid $\mathrm{CO}_{2}$ through reaction 3; (ii) as mentioned before, $\mathrm{CO}_{2}$ can be formed through reaction 1 in apolar ices when the reaction is induced by energetic input.

Laboratory experiments have shown that $\mathrm{CO}_{2}$ is efficiently formed after energetic processing of pure $\mathrm{CO}$ ice and ice mixtures containing $\mathrm{CO}$ and $\mathrm{H}_{2} \mathrm{O}$ (e.g., d'Hendecourt et al. 1986; Moore et al. 1991; Bernstein et al. 1995; Gerakines et al. 1996; Ehrenfreund et al. 1997; Palumbo et al. 1998; Watanabe et al. 2002; Loeffler et al. 2005). Furthermore, $\mathrm{CO}_{2}$ ice can be formed upon irradiation of carbon grains covered by a water cap or an oxygen layer (Mennella et al. 2004, 2006; Gomis \& Strazzulla 2005; Raut et al. 2012; Fulvio et al. 2012). Recently, Ioppolo et al. (2009) and Garozzo et al. (2011) quantitatively studied the formation of $\mathrm{CO}_{2}$ ice upon ion irradiation of interstellar relevant ice mixtures containing $\mathrm{C}$ - and $\mathrm{O}$-bearing species at low $(12-15 \mathrm{~K})$ and high $(40-60 \mathrm{~K})$ temperatures, respectively. Ioppolo et al. (2009) used laboratory data of processed ice to fit the $\mathrm{CO}_{2}$ stretching and bending mode band profiles observed by ISO towards a few high-mass young stellar objects (YSOs). Here we compare new laboratory data, together with those presented in Ioppolo et al. (2009) and Garozzo et al. (2011), with a wider sample of sources in low-mass star forming regions with the intent of constraining the contribution of energetic processing to the formation of solid $\mathrm{CO}_{2}$ in space at different stages of star forming regions (see Tables 4, 5 and the discussion in Sect. 3.3). All the sources have been observed by the Spitzer Space Telescope and listed in Pontoppidan et al. (2008). In the next section the experimental method and data analysis are discussed.

\section{Experimental and data analysis}

\subsection{Experimental}

All the experiments discussed here were performed at the Laboratory for Experimental Astrophysics, INAF - Osservatorio Astrofisico di Catania. The experimental setup depicted in 


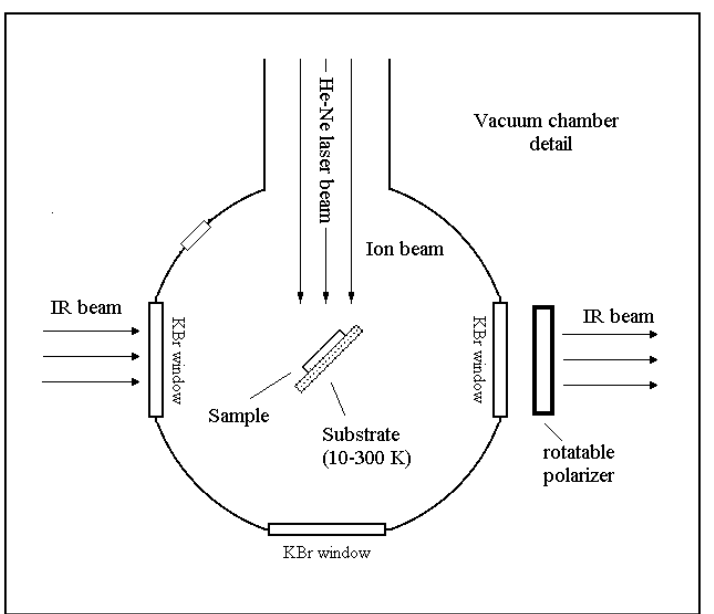

Fig. 1. A schematic top view of the high vacuum chamber.

Fig. 1 comprises a stainless steel high-vacuum chamber $(P<$ $10^{-7}$ mbar) and a $200 \mathrm{kV}$ ions implanter (Danfysik 1080) that can produce, select, accelerate, and collimate ions covering an energy range between 30 and $200 \mathrm{keV}$ (or $400 \mathrm{keV}$ for double ionizations).

Placed in the center of the main chamber, a $\mathrm{KBr}$ or silicon inert substrate is in thermal contact with a closed-cycle helium cryostat. The substrate temperature can be controlled in a range between 10 and $300 \mathrm{~K}$. Gas mixtures were admitted into the main chamber through a needle valve and subsequently deposited on the substrate kept at low temperature. The ice thickness is measured by means of a He-Ne laser as discussed in Baratta \& Palumbo (1998) and Fulvio et al. (2009). The ion beam current density in the ion implanter is always kept below $1 \mu \mathrm{A} \mathrm{cm}^{-2}$ to avoid macroscopic heating of the target. For all the experiments the penetration depth of the impinging ions is greater than the sample thickness $(\sim 0.1 \mu \mathrm{m})$, so that the ice is always uniformly irradiated, as verified using the SRIM code (Ziegler et al. 2008). The substrate forms an angle of $45^{\circ}$ with respect to the ion beam and the IR beam coming from a Fourier transform infrared (FTIR) spectrophotometer (Bruker Equinox 55 or Bruker Vertex 70) that works in the spectral range between $7500-400 \mathrm{~cm}^{-1}(1.33-25 \mu \mathrm{m})$. Transmittance spectra were then easily obtained in situ without tilting the sample. Infrared spectra were always acquired before and after irradiation at low temperatures $(12-17 \mathrm{~K}$ ) and after annealing (up to 90-100 K). A different procedure is used only in one experiment of pure CO ice (Ioppolo et al. 2009), as discussed in the next section. The selection of ice mixture components and ratios is based on observational data from astrophysical literature and includes the most abundant observed interstellar ice molecules, such as water, carbon dioxide, carbon monoxide, methanol, methane, and ammonia. A list of selected laboratory spectra used here to fit IR spectra of astronomical objects is shown in Tables 1 and 2. Spectra are also available in the Catania database ${ }^{1}$. Every label present in the aforementioned tables identifies a specific spectrum with a selected dose of ion irradiation $(\mathrm{eV} / 16 \mathrm{u})$ and temperature. The dose is derived from the knowledge of the stopping power $\left(\mathrm{eV} \times \mathrm{cm}^{2} /\right.$ molecule), calculated by SRIM software (Ziegler et al. 2008), and the ion fluence (ions $\mathrm{cm}^{-2}$ ).

A polarizer is placed in the path of the IR beam in front of the IR detector (Fig. 1). In this way, at each step of an experiment two IR spectra were recorded with a selected component

\footnotetext{
1 At the address: http://www . oact.inaf.it/weblab/
}

of the electric vector parallel ( $\mathrm{P}$ polarization) and perpendicular (S polarization) to the plane of incidence. For each experiment, background spectra in $\mathrm{P}$ and $\mathrm{S}$ were acquired before ice deposition and subtracted to all spectra with the same polarization (Baratta \& Palumbo 1998). Baratta et al. (2000) and Palumbo et al. (2006) also show that when the band profiles obtained in $\mathrm{P}$ and $\mathrm{S}$ polarization are similar, the features seen in the transmittance spectra directly reflect the variation in the absorption coefficient of the solid sample. Under these circumstances a direct comparison between transmission laboratory spectra and astronomical observations is allowed. This is the case for all the band profiles presented here after ion irradiation. Thus, only $\mathrm{P}$ spectra will be considered since the signal-to-noise ratio is higher for this polarization. All $\mathrm{P}$ spectra shown in the following sections were taken with a resolution of $1 \mathrm{~cm}^{-1}$.

\subsection{Data analysis}

Laboratory spectra were acquired in transmittance units $\left(I_{\mathrm{f}}\right)$ and were converted into optical depth units $\tau(v)=\ln \left(I_{0} / I_{\mathrm{f}}\right)$ where $I_{0}$ is the normalization continuum. The column density $\left(N\right.$, molecules $\left.\mathrm{cm}^{-2}\right)$ of species in the solid phase is then calculated using the equation

$N=\frac{\int \tau_{\nu} \mathrm{d} v}{\mathrm{~A}}$

where $\int \tau_{\nu} \mathrm{d} v\left(\mathrm{~cm}^{-1}\right)$ is the area (in optical depth scale) of a selected band and $\mathrm{A}$ is the band strength $\left(\mathrm{cm}\right.$ molecule $\left.{ }^{-1}\right)$. The A-values used in this work are listed in Table 3. The column density is corrected by a factor of

$\cos \theta_{r}=\sqrt{1-\frac{\sin ^{2} \theta_{i}}{n_{\mathrm{f}}^{2}}}$

where $\theta_{r}$ is the refractive angle and $n_{\mathrm{f}}$ the refractive index of the film. This correction takes the increased path length of the IR beam at an angle of incidence $\theta_{i}=45^{\circ}$ into account (Fulvio et al. 2009; Modica \& Palumbo 2010).

\section{Results and discussion}

\subsection{Irradiation of ice mixtures}

All the selected laboratory experiments presented here confirm the formation of $\mathrm{CO}_{2}$ ice upon energetic processing (i.e., ion irradiation) of C-and O-bearing ice mixtures. Ioppolo et al. (2009) calculated the column density of solid carbon dioxide $\left(\mathrm{N}_{\mathrm{CO}_{2}}\right)$ produced in some of the experiments listed in Tables 1 and 2 with respect to the initial abundance of solid $\mathrm{CO}$ or $\mathrm{CH}_{3} \mathrm{OH}\left(N_{\mathrm{X}}\right)$ and as a function of the irradiation dose:

$N_{\mathrm{CO}_{2}}=N_{\mathrm{X}} \times A\left(1-\mathrm{e}^{-\sigma_{\mathrm{tot}} D}\right)$

where $A$ is the asymptotic value for the $\mathrm{CO}_{2}$ column density divided by the initial column density of $\mathrm{CO}$ or $\mathrm{CH}_{3} \mathrm{OH}, \sigma_{\text {tot }}$ is the total cross section in $16 \mathrm{u} / \mathrm{eV}$, and $D$ the dose in $\mathrm{eV} / 16 \mathrm{u}$. For all these experiments the $\mathrm{CO}_{2}$ column density increases rapidly at low doses and then reaches a saturation level indicating that a steady state is always reached between the $\mathrm{CO}_{2}$ formation and destruction mechanisms.

Moreover, as discussed in Ioppolo et al. (2009), the band profile of solid $\mathrm{CO}_{2}$ bending mode is sensitive to mixture and temperature changes. Figure 2 shows the variations in $\mathrm{CO}_{2}$ bending mode band profile upon irradiation and thermal annealing of pure $\mathrm{CO}$ ice (top panels), binary mixtures containing $\mathrm{CO}$ mixed 
Table 1. List of the database spectra relative to irradiation of CO-rich ice samples with $200 \mathrm{keV} \mathrm{H}^{+}$and $30 \mathrm{keV} \mathrm{He}^{+}$.

\begin{tabular}{|c|c|c|c|c|c|c|}
\hline \multirow[t]{2}{*}{ Sample } & \multicolumn{4}{|c|}{ Irradiation } & \multicolumn{2}{|r|}{ Spectrum } \\
\hline & Ion & Dose $(e V / 16 u)$ & Fluence (ions $/ \mathrm{cm}^{2}$ ) & $T(\mathrm{~K})$ & $T(\mathrm{~K})$ & Label \\
\hline $\mathrm{CO}$ & $\mathrm{H}^{+}$ & 1 & $6.25 \times 10^{13}$ & 16 & 16 & CO16K_6.25e13 \\
\hline $\mathrm{CO}$ & $\mathrm{H}^{+}$ & 5 & $2.5 \times 10^{14}$ & 16 & 16 & CO16 K_2.5e14 \\
\hline $\mathrm{CO}$ & $\mathrm{H}^{+}$ & 11 & $5 \times 10^{14}$ & 16 & 16 & CO16K_5e14 \\
\hline $\mathrm{CO}$ & $\mathrm{H}^{+}$ & 21 & $1 \times 10^{15}$ & 16 & 16 & CO 16K_10e15 \\
\hline $\mathrm{CO}$ & $\mathrm{H}^{+}$ & 32 & $1.5 \times 10^{15}$ & 16 & 16 & CO 16K_1.5e15 \\
\hline $\mathrm{CO}$ & $\mathrm{H}^{+}$ & 32 & $1.5 \times 10^{15}$ & 16 & 25 & CO 1.5e15_25 \\
\hline $\mathrm{CO}$ & $\mathrm{H}^{+}$ & 32 & $1.5 \times 10^{15}$ & 16 & 40 & CO $1.5 \mathrm{e} 15 \_40$ \\
\hline $\mathrm{CO}$ & $\mathrm{H}^{+}$ & 32 & $1.5 \times 10^{15}$ & 16 & 50 & CO $1.5 \mathrm{e} 15 \_50$ \\
\hline $\mathrm{CO}$ & $\mathrm{H}^{+}$ & 32 & $1.5 \times 10^{15}$ & 16 & 60 & CO $1.5 \mathrm{e} 15 \_60$ \\
\hline $\mathrm{CO}$ & $\mathrm{H}^{+}$ & 32 & $1.5 \times 10^{15}$ & 16 & 70 & CO $1.5 \mathrm{e} 15 \_70$ \\
\hline $\mathrm{CO}$ & $\mathrm{H}^{+}$ & 32 & $1.5 \times 10^{15}$ & 16 & 80 & CO 1.5e15_80 \\
\hline $\mathrm{CO}$ & $\mathrm{H}^{+}$ & 25 & $1.19 \times 10^{15}$ & 16 & 16 & CO irr_16 \\
\hline $\mathrm{CO}$ & $\mathrm{H}^{+}$ & 25 & $1.19 \times 10^{15}$ & 16 & 70 & CO irr_70 \\
\hline $\mathrm{CO}$ & $\mathrm{H}^{+}$ & 25 & $6.25 \times 10^{12}$ & 70 & 70 & CO irr 70_6. 6.25 e12 \\
\hline $\mathrm{CO}$ & $\mathrm{H}^{+}$ & 26 & $3.75 \times 10^{13}$ & 70 & 70 & CO irr 70_3.75 e13 \\
\hline $\mathrm{CO}$ & $\mathrm{H}^{+}$ & 28 & $7.5 \times 10^{13}$ & 70 & 70 & CO irr 70_7.5 e 13 \\
\hline $\mathrm{CO}$ & $\mathrm{H}^{+}$ & 33 & $3.88 \times 10^{14}$ & 70 & 70 & CO irr 70_3.88 e14 \\
\hline $\mathrm{CO}$ & $\mathrm{H}^{+}$ & 33 & $3.88 \times 10^{14}$ & 70 & 16 & CO irr 70_16 \\
\hline $\mathrm{CO}$ & $\mathrm{H}^{+}$ & 35 & $4.63 \times 10^{14}$ & 16 & 16 & CO irr $70.16 \_\overline{4} .63 \mathrm{e} 14$ \\
\hline $\mathrm{CO}$ & $\mathrm{H}^{+}$ & 40 & $6.5 \times 10^{14}$ & 16 & 16 & CO irr 70.16_6.5 e14 \\
\hline $\mathrm{CO}: \mathrm{H}_{2} \mathrm{O}=10: 1$ & $\mathrm{H}^{+}$ & 28 & $1.31 \times 10^{15}$ & 16 & 16 & $\mathrm{CO}: \mathrm{H}_{2} \mathrm{O}=10: 1 \_16$ \\
\hline $\mathrm{CO}: \mathrm{H}_{2} \mathrm{O}=10: 1$ & $\mathrm{H}^{+}$ & 28 & $1.31 \times 10^{15}$ & 16 & 25 & $\mathrm{CO}: \mathrm{H}_{2} \mathrm{O}=10: 1 \_25$ \\
\hline $\mathrm{CO}: \mathrm{H}_{2} \mathrm{O}=10: 1$ & $\mathrm{H}^{+}$ & 28 & $1.31 \times 10^{15}$ & 16 & 40 & $\mathrm{CO}: \mathrm{H}_{2} \mathrm{O}=10: 1 \_40$ \\
\hline $\mathrm{CO}: \mathrm{H}_{2} \mathrm{O}=10: 1$ & $\mathrm{H}^{+}$ & 28 & $1.31 \times 10^{15}$ & 16 & 60 & $\mathrm{CO}: \mathrm{H}_{2} \mathrm{O}=10: 1 \_60$ \\
\hline $\mathrm{CO}: \mathrm{H}_{2} \mathrm{O}=10: 1$ & $\mathrm{H}^{+}$ & 28 & $1.31 \times 10^{15}$ & 16 & 70 & $\mathrm{CO}: \mathrm{H}_{2} \mathrm{O}=10: 1 \_70$ \\
\hline $\mathrm{CO}: \mathrm{H}_{2} \mathrm{O}=10: 1$ & $\mathrm{H}^{+}$ & 28 & $1.31 \times 10^{15}$ & 16 & 80 & $\mathrm{CO}: \mathrm{H}_{2} \mathrm{O}=10: 1 \_80$ \\
\hline $\mathrm{CO}: \mathrm{H}_{2} \mathrm{O}=10: 1$ & $\mathrm{H}^{+}$ & 28 & $1.31 \times 10^{15}$ & 16 & 90 & $\mathrm{CO}: \mathrm{H}_{2} \mathrm{O}=10: 1 \_90$ \\
\hline $\mathrm{CO}: \mathrm{N}_{2}=8: 1$ & $\mathrm{H}^{+}$ & 23 & $1 \times 10^{15}$ & 16 & 16 & $\mathrm{CO}: \mathrm{N}_{2}=8: 1 \_16$ \\
\hline $\mathrm{CO}: \mathrm{N}_{2}=8: 1$ & $\mathrm{H}^{+}$ & 23 & $1 \times 10^{15}$ & 16 & 40 & $\mathrm{CO}: \mathrm{N}_{2}=8: 1 \_40$ \\
\hline $\mathrm{CO}: \mathrm{N}_{2}=8: 1$ & $\mathrm{H}^{+}$ & 23 & $1 \times 10^{15}$ & 16 & 60 & $\mathrm{CO}: \mathrm{N}_{2}=8: 1 \_60$ \\
\hline $\mathrm{CO}: \mathrm{N}_{2}=8: 1$ & $\mathrm{H}^{+}$ & 23 & $1 \times 10^{15}$ & 16 & 70 & $\mathrm{CO}: \mathrm{N}_{2}=8: 1 \_70$ \\
\hline $\mathrm{CO}: \mathrm{N}_{2}=8: 1$ & $\mathrm{H}^{+}$ & 23 & $1 \times 10^{15}$ & 16 & 80 & $\mathrm{CO}: \mathrm{N}_{2}=8: 1 \_80$ \\
\hline $\mathrm{CO}: \mathrm{N}_{2}=1: 1$ & $\mathrm{H}^{+}$ & 23 & $1 \times 10^{15}$ & 16 & 16 & $\mathrm{CO}: \mathrm{N}_{2}=1: 1 \_16$ \\
\hline $\mathrm{CO}: \mathrm{N}_{2}=1: 1$ & $\mathrm{H}^{+}$ & 23 & $1 \times 10^{15}$ & 16 & 40 & $\mathrm{CO}: \mathrm{N}_{2}=1: 1 \_40$ \\
\hline $\mathrm{CO}: \mathrm{N}_{2}=1: 1$ & $\mathrm{H}^{+}$ & 23 & $1 \times 10^{15}$ & 16 & 60 & $\mathrm{CO}: \mathrm{N}_{2}=1: 1 \_60$ \\
\hline $\mathrm{CO}: \mathrm{N}_{2}=1: 1$ & $\mathrm{H}^{+}$ & 23 & $1 \times 10^{15}$ & 16 & 80 & $\mathrm{CO}: \mathrm{N}_{2}=1: 1 \_80$ \\
\hline $\mathrm{CO}: \mathrm{NH}_{3}=2: 1$ & $\mathrm{He}^{+}$ & 8 & $3.93 \times 10^{14}$ & 12.5 & 12.5 & $\mathrm{CO}: \mathrm{NH}_{3}=2: 1 \_3.93$ e14 \\
\hline $\mathrm{CO}: \mathrm{NH}_{3}=2: 1$ & $\mathrm{He}^{+}$ & 12 & $6.06 \times 10^{14}$ & 12.5 & 12.5 & $\mathrm{CO}: \mathrm{NH}_{3}=2: 1 \_6.06 \mathrm{e} 14$ \\
\hline $\mathrm{CO}: \mathrm{NH}_{3}=2: 1$ & $\mathrm{He}^{+}$ & 19 & $9.18 \times 10^{14}$ & 12.5 & 12.5 & $\mathrm{CO}: \mathrm{NH}_{3}=2: 1 \_9.18$ e14 \\
\hline
\end{tabular}

Table 2. List of the database spectra relative to irradiation of pure methanol ice with $30 \mathrm{keV} \mathrm{He}$.

\begin{tabular}{|c|c|c|c|c|c|}
\hline \multirow[t]{2}{*}{ Sample } & \multicolumn{3}{|c|}{ Irradiation } & \multicolumn{2}{|c|}{ Spectrum } \\
\hline & Ion & Dose $(\mathrm{eV} / 16 \mathrm{u})$ & $T(\mathrm{~K})$ & $T(\mathrm{~K})$ & Label \\
\hline $\mathrm{CH}_{3} \mathrm{OH}$ & $\mathrm{He}^{+}$ & 28 & 12.5 & 12.5 & $\mathrm{CH}_{3} \mathrm{OH} \_12.5$ \\
\hline $\mathrm{CH}_{3} \mathrm{OH}$ & $\mathrm{He}^{+}$ & 28 & 12.5 & 50 & $\mathrm{CH}_{3} \mathrm{OH} \_50$ \\
\hline $\mathrm{CH}_{3} \mathrm{OH}$ & $\mathrm{He}^{+}$ & 28 & 12.5 & 65 & $\mathrm{CH}_{3} \mathrm{OH} \_65$ \\
\hline $\mathrm{CH}_{3} \mathrm{OH}$ & $\mathrm{He}^{+}$ & 28 & 12.5 & 80 & $\mathrm{CH}_{3} \mathrm{OH} \_80$ \\
\hline $\mathrm{CH}_{3} \mathrm{OH}$ & $\mathrm{He}^{+}$ & 28 & 12.5 & 90 & $\mathrm{CH}_{3} \mathrm{OH} \_90$ \\
\hline $\mathrm{CH}_{3} \mathrm{OH}$ & $\mathrm{He}^{+}$ & 28 & 12.5 & 100 & $\mathrm{CH}_{3} \mathrm{OH} \_100$ \\
\hline $\mathrm{CH}_{3} \mathrm{OH}$ & $\mathrm{He}^{+}$ & 28 & 12.5 & 110 & $\mathrm{CH}_{3} \mathrm{OH} \_110$ \\
\hline
\end{tabular}

with $\mathrm{H}_{2} \mathrm{O}, \mathrm{N}_{2}$, and $\mathrm{NH}_{3}$ (central panels), and pure $\mathrm{CH}_{3} \mathrm{OH}$ ice (right-bottom panel). The bending mode band profile of pure $\mathrm{CO}_{2}$ is also shown for comparison (left-bottom panel).

The $\mathrm{CO}_{2}$ bending mode band in pure $\mathrm{CO}_{2}$ ice in $\mathrm{S}$ polarization, as shown in Fig. 2, has two peaks at about 656 and $660 \mathrm{~cm}^{-1}$. When the spectrum is taken in $\mathrm{P}$ polarization an additional peak is present at $676 \mathrm{~cm}^{-1}$ due to the longitudinal optical (LO) mode (see Baratta \& Palumbo 1998; Palumbo et al. 2006). The $\mathrm{CO}_{2}$ bending mode band present in the IR spectra
Table 3. List of the band strength (A) values used here.

\begin{tabular}{lccc}
\hline \hline Molecule & $\begin{array}{c}\text { Band } \\
\left(\mathrm{cm}^{-1}\right)\end{array}$ & $\begin{array}{c}\mathrm{A} \\
(\mathrm{cm} \mathrm{molecule}\end{array}$ & Reference \\
\hline $\mathrm{H}_{2} \mathrm{O}$ & 3300 & $20 \times 10^{-17}$ & Allamandola et al. (1988) \\
$\mathrm{CO}_{2}$ & 2345 & $7.6 \times 10^{-17}$ & Yamada \& Person (1964) \\
$\mathrm{CO}_{2}$ & 660 & $1.1 \times 10^{-17}$ & Gerakines et al. (1995) \\
$\mathrm{CO}$ & 2139 & $1.1 \times 10^{-17}$ & Jiang et al. (1975) \\
$\mathrm{NH}_{3}$ & 1070 & $1.7 \times 10^{-17}$ & Lacy et al. (1998) \\
$\mathrm{CH}_{3} \mathrm{OH}$ & 1020 & $1.3 \times 10^{-17}$ & Palumbo et al. (1999) \\
\hline
\end{tabular}

after irradiation of a pure $\mathrm{CO}$ ice at $16 \mathrm{~K}$ appears as an asymmetric narrow sharp peak $\left(660 \mathrm{~cm}^{-1}\right)$ with a wider wing at lower wavenumbers (Fig. 2 top-left panel). The same peak then broadens upon heating to $40 \mathrm{~K}$. Finally, at $80 \mathrm{~K}$ the $\mathrm{CO}_{2}$ bending mode band has a double peak, which is typical of a $\mathrm{CO}_{2}$-rich environment. This change in the band profile is due to the desorption of the unprocessed $\mathrm{CO}$ ice that starts already at $30 \mathrm{~K}$. The broadening effect and the double peaks are indeed visible in all the panels of Fig. 2 in which a CO-bearing mixture is first irradiated and then annealed. As shown by Ioppolo et al. (2009), in these 

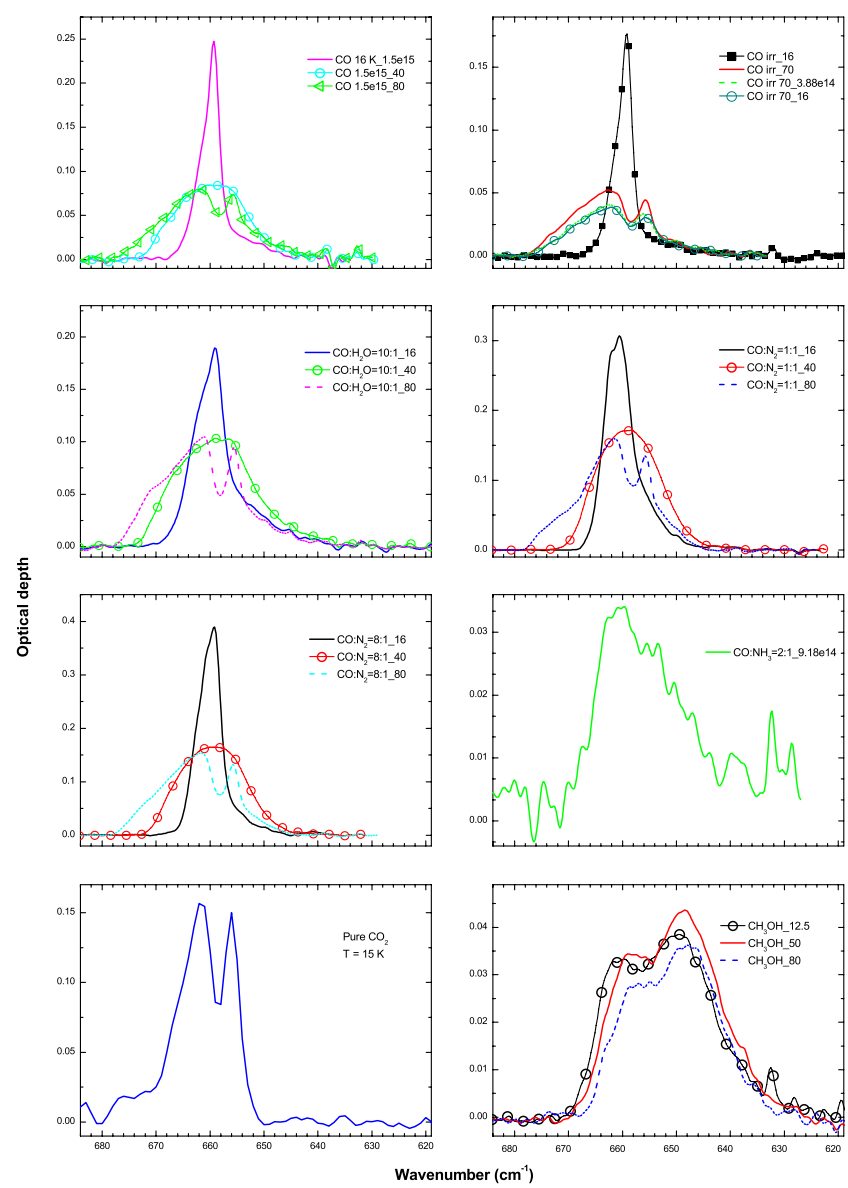

Fig. 2. The bending mode band profile of the carbon dioxide in several ice mixtures irradiated with $200 \mathrm{keV} \mathrm{H}^{+}$or $30 \mathrm{keV} \mathrm{He}^{+}$and annealed. The spectra are acquired with a resolution of $1 \mathrm{~cm}^{-1}$ and the open symbols are only reported for clarity.

instances, the band profile in the spectra taken in $\mathrm{P}$ and $\mathrm{S}$ polarizations are the same. This is because $\mathrm{CO}_{2}$ is not in a pure ice but is mixed with other species, such as carbon chain oxides formed after ion irradiation (see e.g. Palumbo et al. 2008), and is trapped in a refractory residue also formed at low temperature after ion irradiation (Sicilia et al. 2012).

The experiment shown in the top-right panel of Fig. 2 was performed using a different procedure than in the other experiments. The aim in this case was to study changes in the $\mathrm{CO}_{2}$ bending mode band profile upon irradiation at high temperatures when $\mathrm{CO}$ is already desorbed. Therefore, a $\mathrm{CO}$ ice was grown at $16 \mathrm{~K}$, irradiated with $200 \mathrm{keV} \mathrm{H}^{+}$to form $\mathrm{CO}_{2}$ and subsequently heated to $70 \mathrm{~K}$ to then be irradiated further at the same temperature. After irradiation at $70 \mathrm{~K}$ the ice was cooled back to $16 \mathrm{~K}$ and further irradiated. The IR spectra plotted in the top right-hand panel of Fig. 2 show that the double peak is present at $70 \mathrm{~K}$. Further irradiation of the ice slowly decreases the total amount of solid $\mathrm{CO}_{2}$ without changing the profile of the band significantly. Finally, there are no differences within experimental errors between the last spectrum at $70 \mathrm{~K}$ and the one after cooling the sample back to $16 \mathrm{~K}$. When $\mathrm{CO}_{2}$ is formed after irradiation of methanol, the bending mode band profile shows two broad peaks at 650 and $660 \mathrm{~cm}^{-1}$ that shift towards lower wavenumbers when the sample is warmed up.

A general comparison among the IR spectra at the same temperature from all the panels of Fig. 2 confirms that the $\mathrm{CO}_{2}$ vibrational bending mode band profile is strongly sensitive to specific ice mixture (polar and non-polar environment) and ice

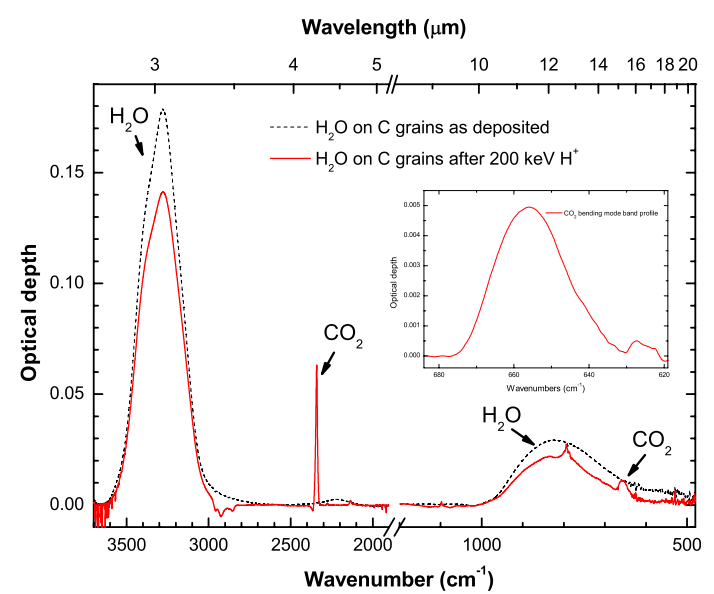

Fig. 3. The mid-IR spectra of water ice covering carbon grains before and after irradiation with $200 \mathrm{keV} \mathrm{H}^{+}$at $17 \mathrm{~K}$. The internal panel shows the newly formed solid $\mathrm{CO}_{2}$ bending mode band profile.

temperature. Thus, the $\mathrm{CO}_{2}$ bending mode band profile is used here to fit the Spitzer observational data presented in the next sections.

\subsection{Irradiation of $\mathrm{H}_{2} \mathrm{O}$ ice on carbon grains}

Carbon grains represent about $20 \%$ of the total interstellar dust grain abundance (Greenberg 1982). In the early stages of a quiescent cloud, water is formed onto these grains, creating a polar ice layer that is then processed by UV radiation and cosmic rays during the evolution of star forming regions. Recently, Mennella et al. (2004, 2006) and Raut et al. (2012) have experimentally proved that solid $\mathrm{CO}$ and $\mathrm{CO}_{2}$ can be formed in cold dark clouds after energetic processing of carbon grains with a water ice cap. Here we present new experimental results from the energetic proton exposure of a layer of water ice covering a carbon sample. The sample is prepared by coating a $\mathrm{KBr}$ substrate with fumes from combusted benzene. A microscopic exam of the sample highlights that carbon residuals aggregate upon deposition onto the $\mathrm{KBr}$ substrate and form irregular prominences that simulate the rough surface of interstellar carbon grains. The resulting amorphous carbon substrate has a surface area wider than the area of an optically flat substrate. The newly formed substrate is then placed in the vacuum chamber and cooled down to $17 \mathrm{~K}$. A layer of $76 \mathrm{~nm}$ of water ice is then deposited onto the rough carbon surface at $17 \mathrm{~K}$ to reproduce interstellar ice mantles in cold dense clouds. Finally, the sample is irradiated with $200 \mathrm{keV}$ protons, and IR transmittance spectra are acquired at different doses.

Figure 3 shows the spectra before and after irradiation of water ice on amorphous carbon at $17 \mathrm{~K}$. For all the other experiments presented in this work the substrate is inert and, therefore, does not influence the investigated surface reactions induced by irradiation of interstellar ice analogs. Here, the irradiated carbon substrate interacts with the water ice and contributes to the formation of solid $\mathrm{CO}_{2}$ at the interface between carbon and ice. The characteristic bending mode feature of solid carbon dioxide in a water environment (small internal panel of Fig. 3) is indeed seen after a fluence of $8.36 \times 10^{15}$ ions $/ \mathrm{cm}^{2}$. The final $\mathrm{CO}_{2}$ column density is about $1.1 \times 10^{16} \mathrm{~mol} / \mathrm{cm}^{2}$.

The $\mathrm{CO}_{2}$ bending mode band profile shown in Fig. 3 is large and already quite symmetric at low temperatures. A similar profile is obtained by irradiating a $\mathrm{CO}: \mathrm{H}_{2} \mathrm{O}=10: 1$ ice sample and subsequently heating it to $40 \mathrm{~K}$ to induce $\mathrm{CO}$ thermal desorption (see Fig. 2). In the latter case, however, the broad $\mathrm{CO}_{2}$ 
Table 4. List of selected low-mass young stellar objects and a field star observed by the Spitzer Space Telescope.

\begin{tabular}{|c|c|c|c|c|c|}
\hline Source & Alias & Cloud & Spectral class & $\begin{array}{c}\mathrm{A}_{\mathrm{V}} \\
(\mathrm{mag})\end{array}$ & References \\
\hline IRAS 13546 -3941 & & BHR 92 (CG 12) & II, I & $>20$ & $1,2,3$ \\
\hline CED 110 IRS 4 & CHSM8415, Cam1-40, ISO84, 11051 -7706 & ChaI & $\mathrm{I} / 0$ & 30 & 4,5 \\
\hline CED 110 IRS 6 & CHSM9387, Cam1-42, ISO92, 11057 -7706 & ChaI & I & 46 & 4,6 \\
\hline CrA IRAS 32 & ISO CrA 182 & $\mathrm{Cr} \mathrm{A}$ & I & $45^{a}$ & 7 \\
\hline CrA IRS 7A & & $\mathrm{CrA}$ & I & 35 & 8,9 \\
\hline R CrA IRS 5 & & $\mathrm{Cr} \mathrm{A}$ & I & 36.7 & $8,10,11$ \\
\hline HH 46 IRS & IRAS $08242-5050$ & HH 46, Vela & I & $32-38$ & 12,1 \\
\hline RNO 91 & IRAS $16316-1540$ & L 43 & II & $27^{b}$ & 8,13 \\
\hline IRAS $03254+3050$ & HH 14 & Perseus, Lynds 1450 & $\mathrm{I}^{c}$ & 11 & 6 \\
\hline IRAS $03271+3013$ & & Perseus & $\mathrm{I}^{c}$ & $\ldots$ & \\
\hline IRAS $03439+3233$ & B5 IRS 3 & Perseus, Barnard 5 & $\mathrm{I}^{c}$ & 13 & 6 \\
\hline IRAS 03445 +3242 & B5 IRS 1, HH 366 & Perseus, Barnard 5 & $I^{c}$ & 23 & 6 \\
\hline RNO 15 & IRAS $03247+3001$ & Perseus & $\mathrm{I} / 0$, or flat ${ }^{c}$ & $\ldots$ & 14 \\
\hline CRBR $2422.8-3423$ & & $\rho \mathrm{Oph}$ & I-II & $\ldots$ & 8 \\
\hline GSS 30 IRS I & & $\rho \mathrm{Oph}$ & I & $\ldots$ & 8 \\
\hline IRS 37 & YLW 12A & $\rho$ Oph & I & $30.1^{d}$ & 15,16 \\
\hline IRS 42 & YLW 13B, ROX 21 & $\rho \mathrm{Oph}$ & I-II & $34.4^{d}$ & 8,15 \\
\hline IRS 43 & YLW 15A & $\rho \mathrm{Oph}$ & I & $43.8^{d}$ & 8,15 \\
\hline IRS 44 & YLW 16A & $\rho \mathrm{Oph}$ & I & $44.0^{d}$ & 8,15 \\
\hline IRS 51 & & $\rho \mathrm{Oph}$ & I-II & $41.6^{d}$ & 8,15 \\
\hline IRS 63 & & $\rho \mathrm{Oph}$ & I-II & 26 & 8,6 \\
\hline WL 6 & & $\rho \mathrm{Oph}$ & I & 47 & 8,17 \\
\hline WL 12 & & $\rho \mathrm{Oph}$ & I & 41 & 8,18 \\
\hline WL $20 \mathrm{~S}$ & & $\rho \mathrm{Oph}$ & $\mathrm{II}^{c}, \mathrm{I}^{e}$ & 25 & $17,19,20$ \\
\hline EC 88 & SVS 4-5 & Serpens & I & $\ldots$ & 8 \\
\hline EC 90 & CK 1, SVS 20 & Serpens & I & $14-20$ & $8,18,6$ \\
\hline EC 92 & SVS 4-10 & Serpens & I & $\ldots$ & \\
\hline EC 118 & CK 2 & Serpens & Background & 46 & 8,18 \\
\hline L 1489 IRS & IRAS $04016+2610$, HH 360 & Taurus & I & 29 & $8,9,6$ \\
\hline DG Tau B & & Taurus & II & $25.5 \pm 3.3 ; 30$ & $8,16,21,22$ \\
\hline
\end{tabular}

Notes. ${ }^{(a)}$ In the RCrA cloud core. ${ }^{(b)}$ Upper limit, according to Myers et al. (1987) with $V$ band at $0.55 \mu$ m. ${ }^{(c)}$ As deduced according to Greene et al. (1994). ${ }^{(d)}$ Upper limit to the visual extinction toward a YSO obtained assuming the intrinsic $(H-K)=0$ (Wilking et al. 1989). ${ }^{(e)}$ According to Ressler \& Barsony (2001).

References. (1) Santos et al. (1998); (2) Bourke et al. (1995); (3) Haikala \& Reipurth (2010); (4) Luhman (2008); (5) Henning et al. (1993); (6) Cook et al. (2011); (7) Wilking et al. (1992); (8) Pontoppidan et al. (2003); (9) Chiar et al. (1998); (10) Castelaz \& Hackwell (1987); (11) Taylor \& Storey (1984); (12) Antonucci et al. (2008); (13) Myers et al. (1987); (14) Evans et al. (2009); (15) Wilking et al. (1989); (16) Onishi et al. (1998); (17) Wilking \& Lada (1983); (18) Chiar et al. (1995); (19) Ressler \& Barsony (2001); (20) Barsony et al. (2002); (21) Kruger et al. (2011); (22) Watson et al. (2004).

bending mode band is asymmetric and the $\mathrm{CO}_{2}$ band broadens only above $30 \mathrm{~K}$. The experiment presented in this section gives a $\mathrm{CO}_{2}$ bending mode broad component at low temperatures that is used to fit observational data as shown in the next sections. Moreover, this experiment simulates the formation of $\mathrm{CO}_{2}$ after energetic processing of water ice on carbon grains under cold molecular cloud conditions. This mechanism, together with the non-energetic routes, can contribute to the total $\mathrm{CO}_{2}$ observed in polar ices in dark clouds. The spectrum plotted in Fig. 3 also shows a downward feature at about $2900 \mathrm{~cm}^{-1}$ assigned to $\mathrm{C}-\mathrm{H}$ bonds in the carbon substrate that are destroyed during irradiation. Other features are present at $2276 \mathrm{~cm}^{-1}\left({ }^{13} \mathrm{CO}_{2}\right), 2136 \mathrm{~cm}^{-1}(\mathrm{CO})$, and $794 \mathrm{~cm}^{-1}$. This feature is tentatively assigned to the $\mathrm{C}-\mathrm{H}$ out-of-plane bending mode of acetylene $\left(\mathrm{C}_{2} \mathrm{H}_{2}\right)$ and/or of aromatic rings with three adjacent hydrogen atoms (Strazzulla \& Baratta 1991). Further studies are, however, needed to confirm this identification.

\subsection{Comparison with observations}

All the selected sources are low-mass YSOs still embedded in their parent thick cloud, emitting in the IR spectral range and belonging to the Lada-Andre spectral classes 0, I, and II. A field star (CK2) is also included in the list. Their radiation was acquired by the Spitzer InfraRed Spectrometer (IRS), which operates into the 5-40 $\mu \mathrm{m}$ range. Pontoppidan et al. (2008) studied and compared the $\mathrm{CO}_{2}$ bending mode band profile from all these sources to laboratory spectra. They find that a five-component fit could reproduce the profile of the $\mathrm{CO}_{2}$ bending mode feature in most of the investigated cases. All their laboratory components correspond to interstellar relevant ice analogs and can be divided into polar and non-polar ices. Unlike our laboratory study in which $\mathrm{CO}_{2}$ is formed in the ice, in Pontoppidan et al. (2008) the $\mathrm{CO}_{2}$ is mixed with other species and subsequently deposited at low temperatures. Among all the available YSO sources in Pontoppidan et al. (2008), we selected those that have spectra with a good signal-to-noise ratio and an optical depth $<1$. Our selection of sources with some of their characteristics is reported in Tables 4 and 5.

In a previous study we compared the $\mathrm{CO}_{2}$ bending mode band profile from some high-mass YSOs observed by ISO satellite with laboratory spectra and proved that the observational $\mathrm{CO}_{2}$ band profile (i.e., band position, width, and shape) can be fitted with a linear combination of different laboratory spectral components (Ioppolo et al. 2009). Here we perform a more extensive and systematic comparison between recent Spitzer 
Table 5. Column density values for $\mathrm{CO}_{2}, \mathrm{CO}, \mathrm{H}_{2} \mathrm{O}, \mathrm{CH}_{3} \mathrm{OH}$ and $\mathrm{NH}_{3}$ along the line of sight to selected young stellar objects and a field star.

\begin{tabular}{|c|c|c|c|c|c|c|}
\hline Source & $N\left(\mathrm{CO}_{2}\right)_{\text {total }}$ & $N(\mathrm{CO})_{\text {solid }^{a}}{ }^{a}$ & $N\left(\mathrm{H}_{2} \mathrm{O}\right)$ & $N\left(\mathrm{CH}_{3} \mathrm{OH}\right)$ & $N\left(\mathrm{NH}_{3}\right)^{b}$ & References \\
\hline IRAS $13546-3941$ & $8.72 \pm 0.12$ & $\ldots$ & $20.7 \pm 2.0$ & $<0.8 \pm 0.1$ & $0.94 \pm 0.16$ & $1,2,3$ \\
\hline CED 110 IRS 4 & $12.26 \pm 0.12$ & $\ldots$ & & $\ldots$ & $\ldots$ & 2 \\
\hline CED 110 IRS 6 & $14.30 \pm 0.08$ & $\ldots$ & $47.0 \pm 6.0$ & 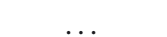 & . & 2 \\
\hline CrA IRAS 32 & $18.70 \pm 0.21$ & $\ldots$ & $52.6 \pm 18.8$ & $<9.5 \pm 3.4$ & $5.44^{c}$ & $1,2,3$ \\
\hline CrA IRS 7A & $19.64 \pm 0.12$ & $14.7 \pm 1.1$ & $108.9 \pm 19.2$ & $<4.1 \pm 0.7$ & $0.97^{c}$ & $1,2,3,4$ \\
\hline R CrA IRS 5 & $14.28 \pm 0.13$ & ( & $35.8 \pm 2.6$ & $2.4 \pm 0.6$ & $0.91 \pm 0.23$ & $1,2,3$ \\
\hline HH 46 IRS (IRAS 08242 -5050) & $21.58 \pm 0.11$ & $15.8 \pm 1.2$ & $77.9 \pm 7.7$ & $4.3 \pm 0.5$ & $4.77 \pm 0.46$ & $1,2,3$ \\
\hline RNO 91 (IRAS 16316 -1540) & $11.66 \pm 0.16$ & $8.0 \pm 0.3$ & $42.5 \pm 3.6$ & $<2.4 \pm 0.2$ & $2.03 \pm 0.30$ & $1,2,3,4$ \\
\hline IRAS $03254+3050$ & $8.86 \pm 0.10$ & $3.1 \pm 1.0$ & $36.6 \pm 4.7$ & $<1.7 \pm 0.2$ & $2.44 \pm 0.39$ & $1,2,3$ \\
\hline IRAS $03271+3013$ & $15.37 \pm 0.09$ & $5.5 \pm 2.7$ & $76.9 \pm 17.6^{d}$ & $<3.3 \pm 0.8$ & $4.90 \pm 0.88$ & $1,2,3$ \\
\hline IRAS $03439+3233$ (B5 IRS 3) & $3.32 \pm 0.06$ & $2.9 \pm 0.9$ & $10.1 \pm 0.9$ & $<0.8 \pm 0.1$ & $0.31^{c}$ & $1,2,3$ \\
\hline IRAS 03445 +3242 (B5 IRS 1) & $7.07 \pm 0.09$ & $11.5 \pm 1.3$ & $22.6 \pm 2.8$ & $<0.8 \pm 0.1$ & $0.47^{c}$ & $1,2,3$ \\
\hline RNO 15 (IRAS $03247+3001$ ) & $2.57 \pm 0.05$ & $3.5 \pm 0.5$ & $6.9 \pm 0.6$ & $0.8 \pm 0.2$ & $0.80 \pm 0.21^{e}$ & $1,2,3$ \\
\hline CRBR $2422.8-3423$ & $10.54 \pm 0.06$ & $31.2 \pm 3.3$ & $41.9 \pm 4.1$ & $<3.9 \pm 0.4$ & $0.52^{c}$ & $1,2,3,4$ \\
\hline GSS 30 IRS I & $3.28 \pm 0.06$ & $1.3 \pm 0.4$ & $15.3 \pm 3.0$ & $\ldots$ & $\ldots$ & 2,4 \\
\hline IRS 37 & $4.05 \pm 0.08$ & $3.9 \pm 0.4$ & $36.5 \pm 5.0$ & $\ldots$ & $\ldots$ & 2 \\
\hline IRS 42 & $4.49 \pm 0.05$ & $4.1 \pm 0.1$ & $19.5 \pm 2.0$ & $\ldots$ & $\ldots$ & 2,4 \\
\hline IRS 43 & $12.26 \pm 0.12$ & $12.0 \pm 0.3$ & $31.5 \pm 4.0$ & $\ldots$ & $\ldots$ & 2,4 \\
\hline IRS 44 & $6.92 \pm 0.08$ & $3.2 \pm 0.5$ & $34.0 \pm 4.0$ & $\ldots$ & $\ldots$ & 2,4 \\
\hline IRS 51 & $9.32 \pm 0.07$ & $31.9 \pm 0.9$ & $22.1 \pm 3.0$ & $\ldots$ & $\ldots$ & 2,4 \\
\hline IRS 63 & $6.84 \pm 0.05$ & $14.3 \pm 0.3$ & $20.4 \pm 3.0$ & $\ldots$ & $\ldots$ & 2,4 \\
\hline WL 6 & $9.33 \pm 0.08$ & $8.0^{1} ; 13.7 \pm 0.7^{2}$ & $41.7 \pm 6.0$ & $\ldots$ & $\ldots$ & $2,4,5$ \\
\hline WL 12 & $4.34 \pm 0.05$ & $3.3^{1} ; 6.1 \pm 0.4^{2}$ & $22.1 \pm 3.0$ & $\ldots$ & $\ldots$ & $2,4,5$ \\
\hline WL $20 \mathrm{~S}$ & $5.02 \pm 0.06$ & $\ldots$ & & $\ldots$ & $\ldots$ & 2 \\
\hline EC 88 (SVS 4-5) & $17.21 \pm 0.10$ & $27.4 \pm 4.1$ & $56.5 \pm 11.3$ & $14.2 \pm 3.5$ & $\sim 2.4$ & $1,2,3,4$ \\
\hline EC 90 (CK 1, SVS 20) & $5.44 \pm 0.05$ & $6.5^{4}$ & $16.9 \pm 1.6$ & $1.2 \pm 0.3$ & $0.67 \pm 0.20$ & $1,2,3,5$ \\
\hline EC 92 (SVS 4-10) & $8.25 \pm 0.05$ & $\ldots$ & $16.9 \pm 1.4$ & $1.9 \pm 0.3$ & $\sim 0.5$ & $1,2,3$ \\
\hline EC 118 (CK 2) & $11.93 \pm 0.21$ & $12.6^{1} ; 34.5 \pm 3.4^{2}$ & $35.7 \pm 3.5$ & $<0.7$ & $\ldots$ & $2,3,4,6$ \\
\hline L 1489 IRS (IRAS $04016+2610$ ) & $16.20 \pm 0.09$ & $6.0 \pm 0.3^{3} ; 9.0 \pm 0.3^{2}$ & $42.6 \pm 5.1$ & $2.1 \pm 0.7$ & $2.31 \pm 0.30$ & $1,2,3,4,7$ \\
\hline DG Tau B & $5.40 \pm 0.06$ & $2.8 \pm 0.9$ & $22.9 \pm 3.9$ & $<1.3 \pm 0.2$ & $0.47^{c}$ & $1,2,3,4$ \\
\hline
\end{tabular}

Notes. All column densities are in $10^{17}$ molecules $\mathrm{cm}^{-2}$. ${ }^{(a)}$ The CO column density is calculated in this paper according to Pontoppidan et al. (2003, 2008). They use a phenomenological decomposition of the CO stretching vibration mode profile into three components: a CO: $\mathrm{H}_{2} \mathrm{O}$ (red) component, a $\mathrm{CO}$ pure (middle) component and a $\mathrm{CO}: \mathrm{CO}_{2}$ (blue) component. ${ }^{(b)}$ Uncertainties are statistical errors from the Gaussian fit, while absolute errors are up to a factor of 2. ${ }^{(c)}$ Values are $3 \sigma$ upper limits. ${ }^{(d)}$ The $13 \mu \mathrm{m} \mathrm{H}_{2} \mathrm{O}$ libration mode is used for $N_{\mathrm{H}_{2} \mathrm{O}}$ determination. The $3 \mu \mathrm{m}$ band is usually used in the other cases. ${ }^{(e)}$ Values are likely upper limits. ${ }^{(1)}$ Chiar et al. (1995). ${ }^{(2)}$ As calculated in this paper according to Pontoppidan et al. (2003). ${ }^{(3)}$ Teixeira et al. (1998). ${ }^{(4)}$ As calculated by Eiroa \& Hodapp (1989) and according to d'Hendecourt \& Allamandola (1986).

References. (1) Bottinelli et al. (2010); (2) Pontoppidan et al. (2008); (3) Boogert et al. (2008); (4) Pontoppidan et al. (2003); (5) Chiar et al. (1995); (6) Knez et al. (2008); (7) Teixeira et al. (1998).

observations and laboratory spectra. The selection criteria in the choice of the laboratory components are based on the fact that the $\mathrm{CO}_{2}$ bending mode band profile observed towards several YSOs can present different characteristic features:

- a double-peaked structure, in the $660-655 \mathrm{~cm}^{-1}$ spectral range;

- a narrow single-peak profile, at about $660 \mathrm{~cm}^{-1}$;

- a shoulder at lower wavenumbers (at about $650 \mathrm{~cm}^{-1}$ );

- a broad component of the spectrum, peaked at about $655 \mathrm{~cm}^{-1}$.

Figures 2 and 3 show that these characteristic features correspond to certain chemical-physical conditions: a doubly peaked bending mode band profile is due to the segregation of carbon dioxide (e.g., Ehrenfreund et al. 1999; Palumbo \& Baratta 2000), which can be induced by heating of the interstellar ices, hence desorption of volatile species; a narrow single peak suggests that $\mathrm{CO}_{2}$ is at low temperatures in a $\mathrm{CO}$ environment; a shoulder around lower wavenumbers can be caused by the interaction between solid $\mathrm{CO}_{2}$ and alcohols; a broad $\mathrm{CO}_{2}$ band is generally obtained when $\mathrm{CO}_{2}$ is formed by irradiation of water ice on carbon grains at low temperatures. A home-written software (Polyfit, realized by Spinella) is then used to compare observational spectra with laboratory data. The program gives a linear combination of up to five preselected laboratory spectra as a best fit. The bestfit results are presented in Figs. 4-5.

In all the panels of these figures the observational data are always represented by open squares and the fits by solid thick lines. Good agreement is always reached between observational data and a combination of a minimum of two laboratory spectra. Although the fits are not unique, all our fits can reproduce the observed $\mathrm{CO}_{2}$ bending mode band profile towards the selected YSOs.

\subsection{Observational constraints}

To verify that our fits are compatible with the observational data available for each source, we first considered the solid CO and $\mathrm{H}_{2} \mathrm{O}$ column density values (see Table 5), as reported by Pontoppidan et al. $(2003,2008)$ and Boogert et al. (2008), and calculated the $\mathrm{CO} / \mathrm{H}_{2} \mathrm{O}$ column density ratio. In agreement with Cook et al. (2011), we noticed a correspondence between the $\mathrm{CO} / \mathrm{H}_{2} \mathrm{O}$ ratio and the observed $\mathrm{CO}_{2}$ bending mode band profile. In particular, the band profile presents a double-peaked feature 

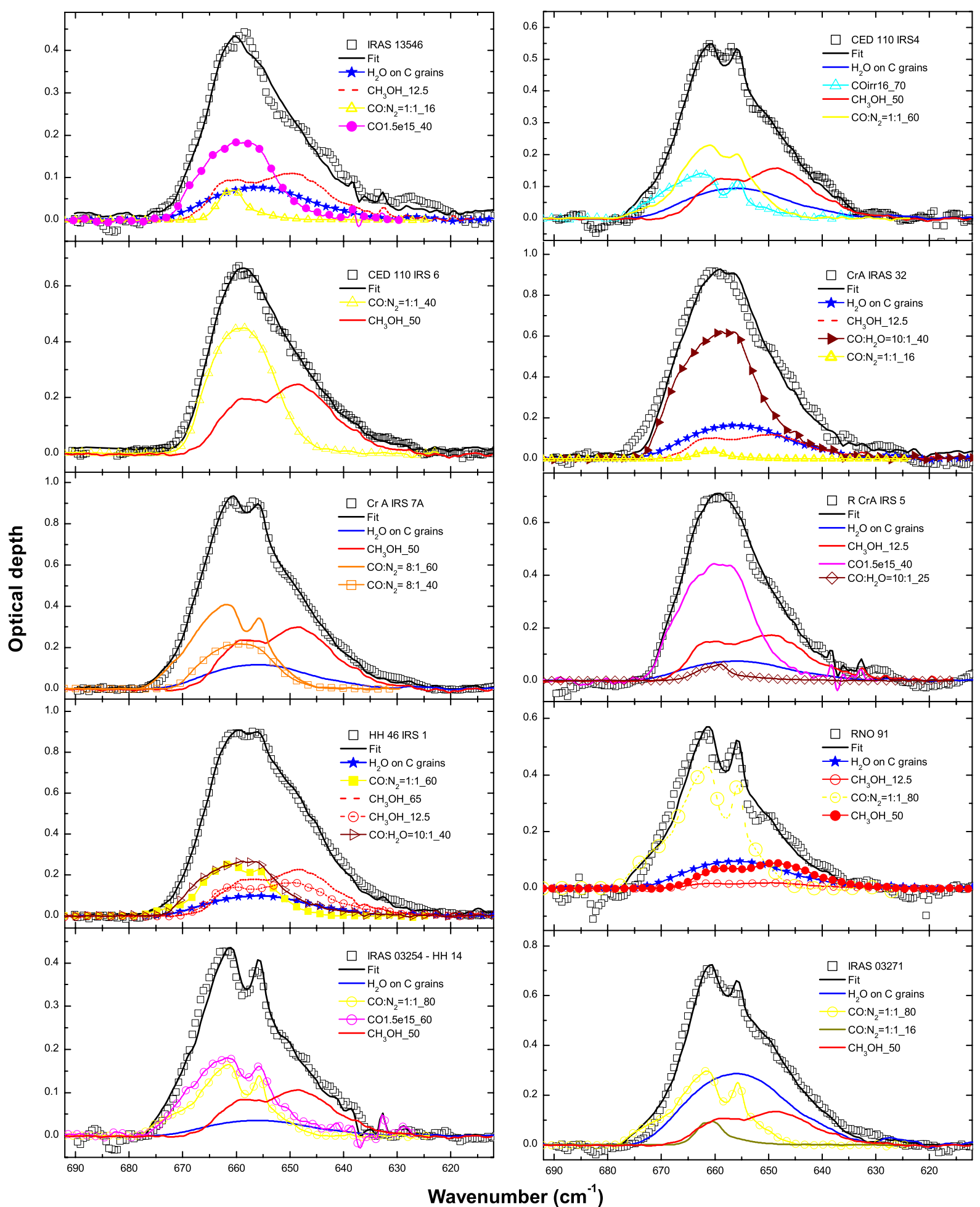

Fig. 4. Comparison between the $\mathrm{CO}_{2}$ bending mode band profile towards several low-mass young stellar objects (open squares) and laboratory spectra. The spectra are acquired with a resolution of $1 \mathrm{~cm}^{-1}$ and the symbols are only reported for clarity. The fits are represented by solid thick lines.

when the $\mathrm{CO} / \mathrm{H}_{2} \mathrm{O}$ ratio is lower than about 0.4 , while for higher values (as high as 1.44 in the case of IRS51), the band profile presents a single peak (see Figs. 4-5). The different $\mathrm{CO} / \mathrm{H}_{2} \mathrm{O}$ ratio is expected to be related to the temperature of the icy grain mantles along the line of sight. In fact, high temperatures favor CO sublimation. Therefore, we used laboratory spectra at low temperature $(T=16-40 \mathrm{~K})$ to fit the $\mathrm{CO}_{2}$ band profile for high $\mathrm{CO} / \mathrm{H}_{2} \mathrm{O}$ values, and we considered laboratory spectra at higher temperature $(T>40 \mathrm{~K})$, which show the double-peaked feature, to fit the $\mathrm{CO}_{2}$ band profile for low $\mathrm{CO} / \mathrm{H}_{2} \mathrm{O}$ values. The column density of $\mathrm{CH}_{3} \mathrm{OH}$ observed towards the sources considered here is reported by Bottinelli et al. (2010) and Boogert et al. (2008), and is listed in Table 5. Although the $\mathrm{CH}_{3} \mathrm{OH}$ abundance is quite low with respect to water for all our sources, this component is an important ingredient for fitting the $\mathrm{CO}_{2}$ "shoulder" at the lower wavenumbers present in the observed spectra. 
S. Ioppolo et al.: Solid $\mathrm{CO}_{2}$ in low-mass young stellar objects
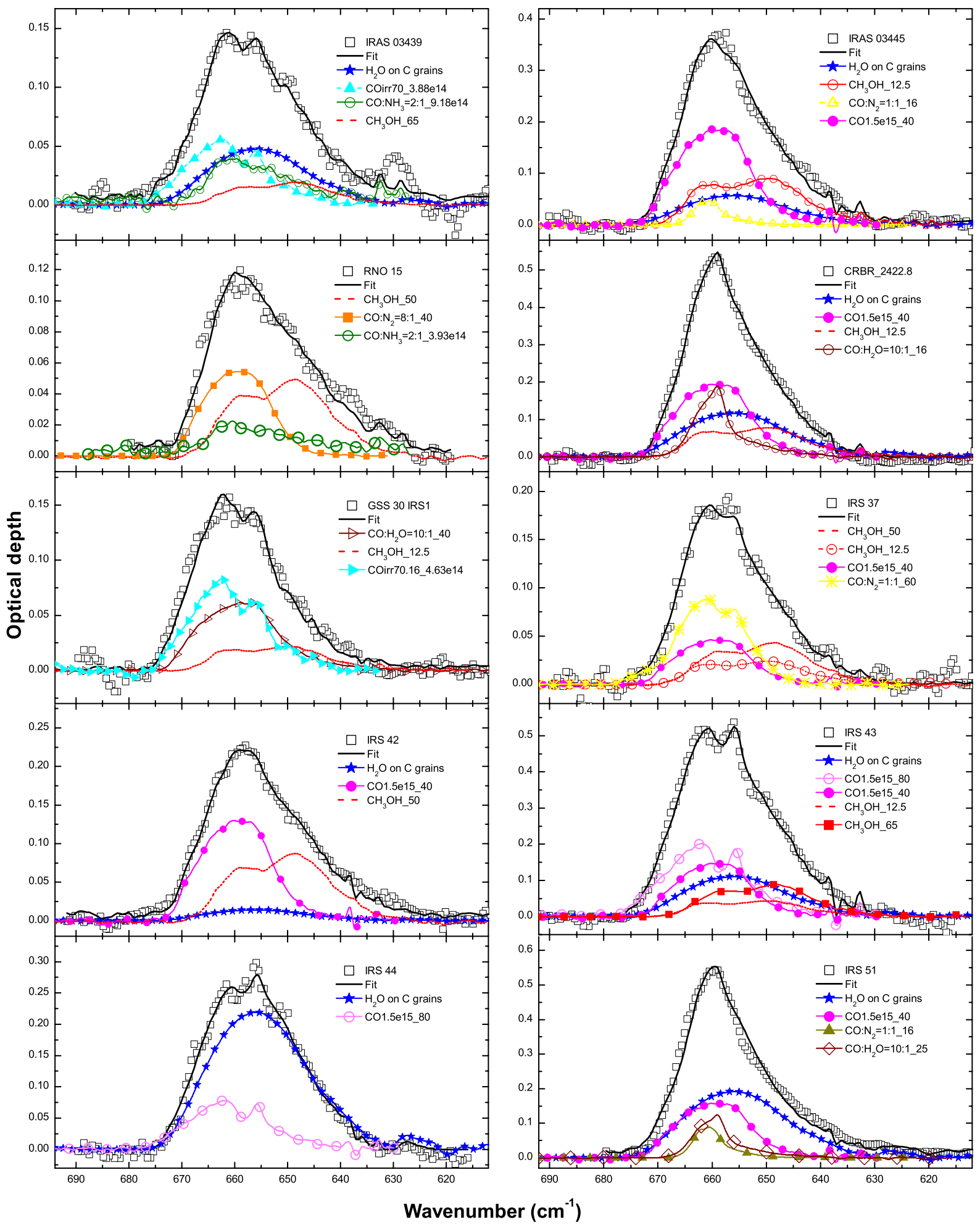

Fig. 4. continued.

The next step is to extend laboratory results (i.e., laboratory column densities, formation and destruction rates) to the interstellar medium. Concerning the $\mathrm{CO}_{2}$ formed after irradiation of $\mathrm{H}_{2} \mathrm{O}$ ice on carbon grains, following Mennella et al. (2004, 2006) and Ioppolo et al. (2009), we assume that the $\mathrm{CO}_{2}$ column density produced in a cloud lifetime of $t=3 \times 10^{7}$ years is $N\left(\mathrm{CO}_{2}\right)=9.3 \times 10^{15} A_{V}$, where $A_{V}$ is the visual extinction of the cloud. The values of $\mathrm{CO}_{2}$ column density expected to be formed after irradiation of carbon grains covered by an ice mantle are reported in Table 6 for some selected sources whose $A_{V}$ is known. As extensively explained in Ioppolo et al. (2009), these values are to be considered as upper limits. The same table also lists the contribution to the fit given by $\mathrm{CO}_{2}$ formed after irradiation of $\mathrm{H}_{2} \mathrm{O}$ ice on carbon grains. Following Ioppolo et al. (2009), for the sources in which the methanol column density is known, we calculated the expected interstellar $\mathrm{CO}_{2}$ column density formed 

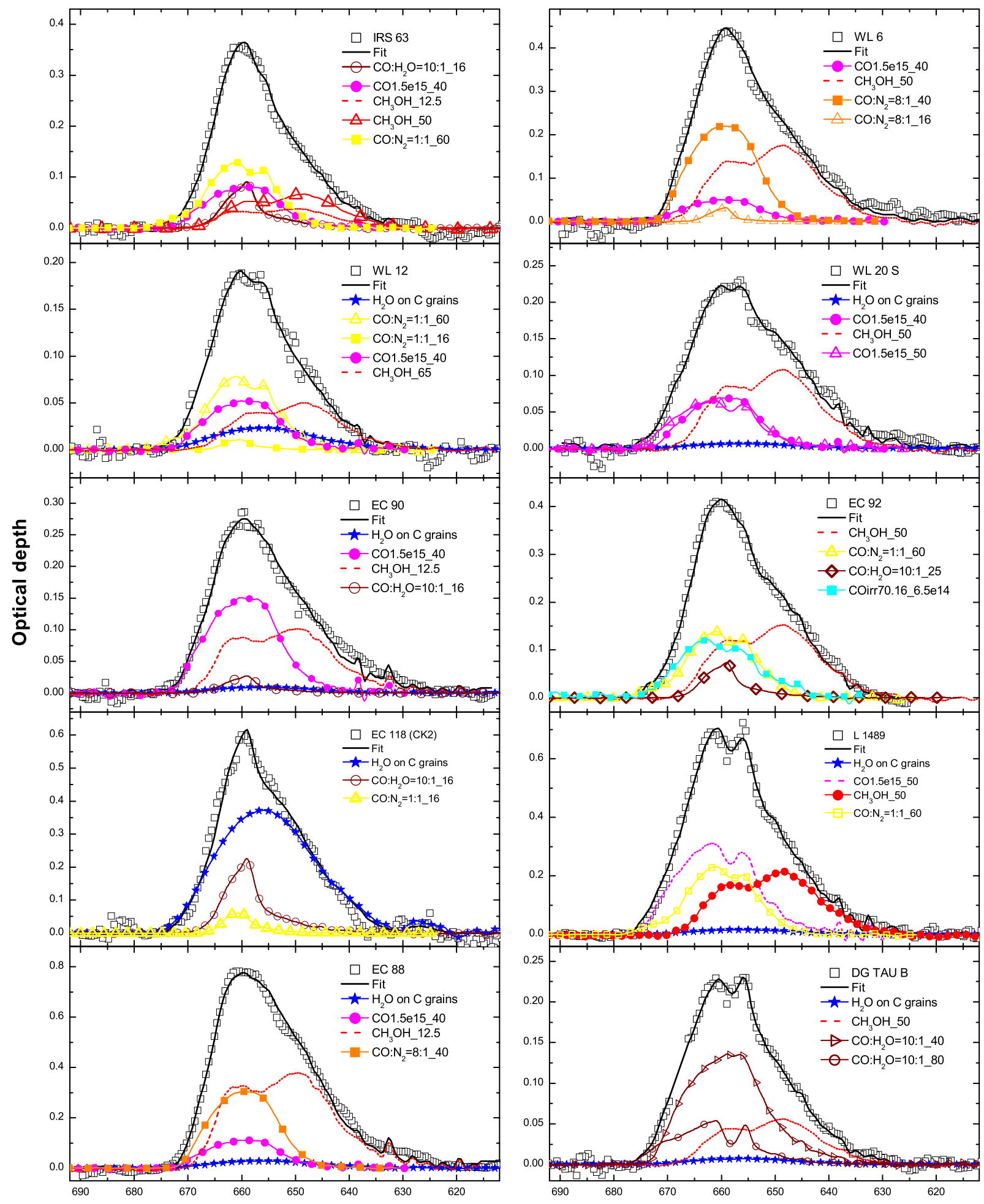

Wavenumber $\left(\mathrm{cm}^{-1}\right)$

Fig. 5. As for Fig. 4. Here a field star is also compared to laboratory data.

after cosmic irradiation of $\mathrm{CH}_{3} \mathrm{OH}$ ice (see Table 7) by using the following formula:

$N\left(\mathrm{CO}_{2}\right)=N\left(\mathrm{CH}_{3} \mathrm{OH}\right)_{\text {obs }} \times\left[\frac{N\left(\mathrm{CO}_{2}\right)}{N\left(\mathrm{CH}_{3} \mathrm{OH}\right)}\right]_{\text {lab }}$

where $N\left(\mathrm{CH}_{3} \mathrm{OH}\right)$ is the residual $\mathrm{CH}_{3} \mathrm{OH}$ column density after irradiation and the expression $\left[\frac{N\left(\mathrm{CO}_{2}\right)}{N\left(\mathrm{CH}_{3} \mathrm{OH}\right)}\right]$ lab has a value of 2.36 according to the ratio between the laboratory band areas and the respective band strength (see Table 3), and assuming a cloud lifetime of $t=3 \times 10^{7}$ years. We point out that the ratio $\left[\frac{N\left(\mathrm{CO}_{2}\right)}{N\left(\mathrm{CH}_{3} \mathrm{OH}\right)}\right]$ lab here defined is different from the ratio $N_{\mathrm{CO}_{2}} / N_{\mathrm{X}}$ defined in Eq. (6). As above, the expected column density derived from Eq. (7) is to be considered an upper limit. Tables 6 and 7 list the expected column density of $\mathrm{CO}_{2}$ formed after irradiation 
Table 6. Expected solid $\mathrm{CO}_{2}$ (upper limits) formed after cosmic ion irradiation of water ice onto carbon grains (Ioppolo et al. 2009) for some selected sources for which $A_{V}$ is known compared to the column density of $\mathrm{CO}_{2}$ in water ice as obtained by the fit.

\begin{tabular}{l|c|c}
\hline \hline Source & $\mathrm{CO}_{2}$ from $\mathrm{H}_{2} \mathrm{O}$ on carbon grains $+200 \mathrm{keV} \mathrm{H}^{+}$ \\
\hline & Expected $\mathrm{CO}_{2}$ column density $\left(\mathrm{mol} \mathrm{cm}^{-2}\right)$ & Obtained $\mathrm{CO}_{2}$ column density (fit) $\left(\mathrm{mol} \mathrm{cm}^{-2}\right)$ \\
R Cr A IRS 5 & $3.41 \times 10^{17}$ & $1.62 \times 10^{17}$ \\
HH 46 IRS (IRAS 08242 -5050) & $3.26 \times 10^{17}$ & $2.15 \times 10^{17}$ \\
EC 90 (CK 1, SVS 20) & $1.58 \times 10^{17}$ & $1.97 \times 10^{16}$ \\
EC 118 (CK 2) & $4.28 \times 10^{17}$ & $8.19 \times 10^{17}$ \\
L 1489 IRS (IRAS 04016 +2610) & $2.70 \times 10^{17}$ & $3.49 \times 10^{16}$ \\
\hline
\end{tabular}

Table 7. Expected solid $\mathrm{CO}_{2}$ (upper limits) formed after cosmic ion irradiation of $\mathrm{CH}_{3} \mathrm{OH}$ ice based on laboratory data (Ioppolo et al. 2009) for some selected sources for which $\mathrm{CH}_{3} \mathrm{OH}$ column density is known compared to the column density of $\mathrm{CO}_{2}$ formed from methanol as obtained by the fit.

\begin{tabular}{l|c|c}
\hline \hline Source & \multicolumn{2}{|c}{$\mathrm{CO}_{2}$ from $\mathrm{CH}_{3} \mathrm{OH}+30 \mathrm{keV} \mathrm{He}^{+}$} \\
\hline & Expected $\mathrm{CO}_{2}$ column density $\left(\mathrm{mol} \mathrm{cm}^{-2}\right)$ & Obtained $\mathrm{CO}_{2}$ column density (fit) $\left(\mathrm{mol} \mathrm{cm}^{-2}\right)$ \\
R Cr A IRS 5 & $5.66 \times 10^{17}$ & $3.79 \times 10^{17}$ \\
HH 46 IRS 1 (IRAS 08242 -5050) & $1.01 \times 10^{18}$ & $8.18 \times 10^{17}$ \\
EC 90 (CK 1, SVS 20) & $2.83 \times 10^{17}$ & $2.22 \times 10^{17}$ \\
L 1489 IRS (IRAS 04016 +2610) & $4.96 \times 10^{17}$ & $4.38 \times 10^{17}$ \\
\hline
\end{tabular}

of carbon grains covered by an ice mantle and after irradiation of $\mathrm{CH}_{3} \mathrm{OH}$, assuming a cloud lifetime of $3 \times 10^{7}$ years and the $\mathrm{CO}_{2}$ column density as given by the fit.

From a general analysis of all the fits shown in this work and the fit of the source Elias 16 (a field star) shown by Mennella et al. (2006), we notice that towards field stars: (i) 70-90\% of the $\mathrm{CO}_{2}$ bending mode profile is due to $\mathrm{CO}_{2}$ formed after irradiation of carbon grains covered by water ice; (ii) the component due to irradiation of methanol is not required; and (iii) the component due to irradiation of CO-rich ice mantles is less than $20 \%$ of total $\mathrm{CO}_{2}$. On the other hand, towards embedded objects: (i) about $2-30 \%$ of the $\mathrm{CO}_{2}$ bending mode profile is due to $\mathrm{CO}_{2}$ formed after irradiation of carbon grains covered by water ice; (ii) the component due to irradiation of methanol is generally required; and (iii) the component due to irradiation of CO-rich ice mantles is as high as $20-70 \%$ with respect to total $\mathrm{CO}_{2}$. The last point (iii) is compatible with the high depletion of volatile gas phase species observed in starless cores (e.g. Caselli et al. 1999), which are the precursors of embedded objects.

The irradiation doses used in all our experiments correspond to an irradiation time for an interstellar cloud of $10^{7}-10^{8}$ years (Ioppolo et al. 2009), which is compatible with the aforementioned cloud lifetimes. Moreover, as displayed in Tables 6 and 7 , we found that our fits are also compatible with the known $A_{V}$ values and observed $\mathrm{CH}_{3} \mathrm{OH}$ column density. Therefore, the choice of these fits is constrained by laboratory results that indicate the irradiation of C- and O-bearing ices as an important and efficient mechanism to form interstellar $\mathrm{CO}_{2}$ ice in YSOs. Only in the case of a quiescent cloud, namely EC 118 (CK2), the expected $\mathrm{CO}_{2}$ column density formed upon energetic input cannot explain the observed abundances. A similar conclusion is obtained by applying the same calculations to the fit of the $\mathrm{CO}_{2}$ bending mode towards the field star Elias 16 shown by Mennella et al. (2006). Although these are only two sources, this result to be confirmed along the line of sight to different quiescent clouds gives an indirect indication that $\mathrm{CO}_{2}$ can also be formed in a early cloud stage through a different mechanism than for cosmic ray irradiation (e.g., surface reactions induced by non-energetic mechanisms; Oba et al. 2010; Ioppolo et al. 2011; Noble et al. 2011). In a later stage, when ices are exposed to higher UV and cosmic ray doses, the total abundance of $\mathrm{CO}_{2}$ is strongly affected by energetic formation mechanisms.

\section{Conclusions}

This laboratory work shows that the vibrational bending mode band profile of solid carbon dioxide is sensitive to ice composition and temperature, and in general, is asymmetric. This has been also observed along the line of sight towards several young stellar objects. These sources indeed suffer from a strong thermal gradient. As a consequence, volatile species can sublimate in the inner regions close to the protostar, UV photons are adsorbed by the envelope itself, while in the most external regions the temperature remains at $10-20 \mathrm{~K}$.

It has been suggested (e.g. Palumbo et al. 1998; Teixeira et al. 1998) that low-energy ( MeV) cosmic rays can be responsible for the ion irradiation of $\mathrm{C}$ - and O-bearing interstellar ice mantles $(10-70 \mathrm{~K})$. Here we give experimental proof that the ion irradiation of ices is one of the most efficient mechanisms for forming new species on interstellar grains. This finding has been achieved by a qualitative and quantitative comparison between observational and laboratory data. A more extensive future work will shed light on the importance of surface reactions induced by non-energetic processes in the early stages of quiescent molecular clouds.

Acknowledgements. We thank F. Spinella for his technical support. This research is in part funded by the LASSIE Initial Training Network, which is supported by the European Community's Seventh Framework Program (FP7/20072013) under Grant Agreement Number 238258. Support for S.I. from the Niels Stensen Fellowship and the Marie Curie Fellowship (FP7-PEOPLE-2011-IOP300957) is gratefully acknowledged.

\section{References}

Allamandola, L. J., Sandford, S. A., \& Valero, G. J. 1988, Icarus, 76, 225 Allamandola, L. J., Sandford, S. A., \& Tielens, A. G. G. M. 1992, ApJ, 399, 134 Antonucci, S., Nisini, B., Giannini, T., \& Lorenzetti, D. 2008, A\&A, 479, 503 Baragiola, R. A. 2003, in Water in Confining Geometries, eds. V. Buch, \& J. P. Devlin (Berlin, Heidelberg: Springer-Verlag), 359

Baratta, G. A., \& Palumbo, M. E. 1998, J. Opt. Soc. Am. A, 15, 3076

Baratta, G. A., Palumbo, M. E., \& Strazzulla, G. 2000, A\&A, 357, 1045

Barsony, M., Greene, T. P., \& Blake, G. A. 2002, ApJ, 572, L75

Bernstein, M. P., Sandford, S. A., Allamandola, L. J., Chang, S., \& Scharberg, M. A. 1995, ApJ, 454, 327

Boogert, A. C. A., Pontoppidan, K. M., Lahuis, F., et al. 2004, ApJS, 154, 359 Boogert, A. C. A., Pontoppidan, K. M., Knez, C., et al. 2008, ApJ, 678, 985 Boonman, A. M. S., van Dishoeck, E. F., Lahuis, F., \& Doty, S. D. 2003, A\&A, 399, 1063 
Bottinelli, S., Boogert, A. C., Bouwman, J., et al. 2010, ApJ, 718, 1100 Bourke, T. L., Hyland, A. R., \& Robinson, G. 1995, MNRAS, 276, 1052 Caselli, P., Walmsley, C. M., Tafalla, M., Dore, L., \& Myers, P. C. 1999, ApJ, 523, L165

Castelaz, M. W., \& Hackwell, J. A. 1987, ApJ, 314, 317

Chiar, J. E., Adamson, A. J., Kerr, T. H., \& Whittet, D. C. B. 1995, ApJ, 455, 234

Chiar, J. E., Gerakines, P. A., \& Whittet, D. C. B. 1998, ApJ, 498, 716

Cook, A. M., Whittet, D. C. B., Shenoy, S. S., et al. 2011, ApJ, 730, 124

Dartois, E., Demyk, K., d'Hendecourt, L., \& Ehrenfreund, P. 1999, A\&A, 351, 1066

Ehrenfreund, P., Boogert, A. C. A., Gerakines, P. A., Tielens, A. G. G. M., \& van Dishoeck, E. F. 1997, A\&A, 328, 649

Ehrenfreund, P., Kerkhof, O., Schutte, W. A., et al. 1999, A\&A, 350, 240

Eiroa, C., \& Hodapp, K.-W. 1989, A\&A, 210, 345

Evans, N. J., Dunham, M. M., Jorgensen, J. K., et al. 2009, ApJS, 181, 321

Fulvio, D., Sivaraman, B., Baratta, G. A., et al. 2009, Spectrochimica Acta A, 72,1007

Fulvio, D., Raut, U., \& Baragiola, R. A. 2012, ApJ, 752, L33

Gálvez, O., Ortega, I. K., Maté, B., et al. 2007, A\&A, 472, 691

Gálvez, O., Maté, B., Herrero, V. J., \& Escribano, R. 2008, Icarus, 197, 599

Garozzo, M., La Rosa, L., Kanuchova, Z., et al. 2011, A\&A, 528, A118

Garrod, R. T., \& Pauly, T. 2011, ApJ, 735, 15

Gerakines, P. A., Schutte, W. A., Greenberg, J. M., \& van Dishoeck, E. F. 1995, A\&A, 296, 810

Gerakines, P. A., Schutte, W. A., \& Ehrenfreund, P. 1996, A\&A, 312, 289

Gerakines, P. A.,Whittet, D. C. B., Ehrenfreud, P., et al. 1999, ApJ, 522, 357

Gibb, E. L., Whittet, D. C. B., Boogert, A. C. A., \& Tielens, A. G. G. M. 2004 , ApJS, 151, 35

Gomis, O., \& Strazzulla, G. 2005, Icarus, 177, 570

Goumans, T. P. M., \& Andersson, S. 2010, MNRAS, 406, 2213

Goumans, T. P. M., Uppal, M. A., \& Brown, W. A. 2008, MNRAS, 384, 1158

Greenberg, J. M. 1982, in Comets, ed. L. L. Wilkening (Tucson: The University of Arizona Press), 131

Greene, T. P., Wilking, B. A., Andrè, P., Young, E. T., \& Lada, C. J. 1994, ApJ, 434,614

Grim, R. J. A., \& d'Hendecourt, L. B. 1986, A\&A, 167, 161

Haikala, L. K., \& Reipurth, B. 2010, A\&A, 510, A1

d'Hendecourt, L. B., \& Allamandola, L. J. 1986, A\&AS, 64, 453

d'Hendecourt, L. B., \& Jourdain de Muizon, M. 1989, A\&A, 223, L5

d'Hendecourt, L. B., Allamandola, L. J., Grim, R. J. A., \& Greenberg, J. M. 1986, A\&A, 158, 119

Henning, Th., Pfau, W., Zinnecker, H., \& Prusti, T. 1993, A\&A, 276, 129

Hudgins, D. M., Sandford, S. A., Allamandola, L. J., \& Tielens, A. G. G. M. 1993, ApJS, 86, 713

Ioppolo, S., Palumbo, M. E., Baratta, G. A., \& Mennella, V. 2009, A\&A, 493, 1017

Ioppolo, S., Cuppen, H. M., van Dishoeck, E. F., \& Linnartz, H. 2011, MNRAS, 413, 2281

Jenniskens, P., Baratta, G. A., Kouchi, A., et al. 1993, A\&A, 273, 583

Jiang, G. J., Person, W. B., \& Brown, K. G. 1975, J. Chem. Phys., 62, 1201

Knez, C., Moore, M., Travis, S., et al. 2008, Organic Matter in Space, eds. S. Kwok, \& S. Sandford, Proc. IAU Symp., 251,

Kruger, A. J., Richter, M. J., Carr, J. R., et al. 2011, ApJ, 729, 145

Lacy, J. H., Faraji, H., Sandford, S. A., \& Allamandola, L. J. 1998, ApJ, 501, L105

Loeffler, M. J., Baratta, G. A., Palumbo, M. E., Strazzulla, G., \& Baragiola, R. A. 2005, A\&A, 435, 587

Luhman, K. L. 2008, Handbook of Star Forming Regions Vol. II, ed. B. Reipurth (ASP)
Madzunkov, S., Shortt, B. J., MacAskill, J. A., Darrach, M. R., \& Chutjian, A. 2006, Phys. Rev. A, 73, 02091

Mennella, V., Baratta, G. A., Esposito, A., Ferini, G., \& Pendleton, Y. J. 2003, ApJ, 587, 727

Mennella, V., Palumbo, M. E., \& Baratta, G. A. 2004, ApJ, 615, 1073

Mennella, V., Baratta, G. A., Palumbo, M. E., \& Bergin, E. A. 2006, ApJ, 643, 923

Modica, P., \& Palumbo, M. E. 2010, A\&A, 519, A22

Moore, M. H., Khanna, R., \& Donn, B. 1991, J. Geophys. Res., 96, 17541

Myers, P. C., Fuller, G. A., Mathieu, R. D., et al. 1987, ApJ, 319, 340

Noble, J. A., Dulieu, F., Congiu, E., \& Fraser, H. J. 2011, ApJ, 735, 121

Nummelin, A., Whittet, D. C. B., Gibb, E. L., Gerakines, P. A., \& Chiar, J. E. 2001, ApJ, 558, 185

Oba, Y., Watanabe, N., Kouchi, A., Hama, T., \& Pirronello, V. 2010, ApJ, 712, L174

Oba, Y., Watanabe, N., Hama, T., et al. 2012, ApJ, 749, 67

Öberg, K., Boogert, A. C. A., Pontoppidan, K. M., et al. 2008, ApJ, 678, 1032

Öberg, K., Boogert, A. C. A., Pontoppidan, K. M., et al. 2011, ApJ, 740, 109

Onishi, T., Mizuno, A., Kawamura, A., et al. 1998, ApJ, 502, 296

Palumbo, M. E., \& Baratta, G. A. 2000, A\&A, 361, 298

Palumbo, M. E., Baratta, G. A., Brucato, J. R., et al. 1998, A\&A, 334, 247

Palumbo, M. E., Castorina, A. C., \& Strazzulla, G. 1999, A\&A, 342, 551

Palumbo, M. E., Baratta, G. A., Collings, M. P., \& McCoustra, M. R. S. 2006, Phys. Chem. Chem. Phys., 8, 279

Palumbo, M. E., Leto, P., Siringo, C., \& Trigilio, C. 2008, ApJ, 685, 1033

Pontoppidan, K. M., Fraser, H. J., Dartois, E., et al. 2003, A\&A, 408, 981

Pontoppidan, K. M., Dullemond, C. P., van Dishoeck, E. F., et al. 2005, ApJ, 622,463

Pontoppidan, K. M., Boogert, A. C. A., Fraser, H. J., et al. 2008, ApJ, 678, 1005

Prasad, S. S., \& Tarafdar, S. P. 1983, ApJ, 267, 603

Raut, U., Fulvio, D., Loeffler, M. J., \& Baragiola, R. A. 2012, ApJ, 752, 159

Ressler, M. E., \& Barsony, M. 2001, AJ, 121, 1098

Romanzin, C., Ioppolo, S., Cuppen, H. M., van Dishoeck, E. F., \& Linnartz, H. 2011, J. Chem. Phys., 134, 084504

Roser, J. E., Vidali, G., Manicò, G., \& Pirronello, V. 2001, ApJ, 555, L61

Ruffle, D. P., \& Herbst, E. 2001, MNRAS, 324, 1054

Sandford, S. A., \& Allamandola, L. J. 1990, ApJ, 355, 357

Santos, N. C., Yun, J. L., Santos, C. A., \& Marreiros, R. G. 1998, AJ, 116, 1376

Sicilia, D., Ioppolo, S., Vindigni, T., Baratta, G. A., \& Palumbo, M. E. 2012, A\&A, 543, A155

Strazzulla, G., \& Baratta, G. A. 1991, A\&A, 241, 310

Talbi, D., Chandler, G. S., \& Rohl, A. L. 2006, Chem. Phys., 320, 214

Taylor, K. N. R., \& Storey, J. W. V. 1984, MNRAS, 209, 5

Teixeira, T. C., Emerson, J. P., \& Palumbo, M. E. 1998, A\&A, 330, 711

Tielens, A. G. G. M., \& Hagen, W. 1982, A\&A, 114, 245

van Dishoeck, E. F., Helmich, F. P., de Graauw, T., et al. 1996, A\&A, 315, L349

Watanabe, N., \& Kouchi, A. 2002, ApJ, 567, 651

Watson, D. M., Kemper, F., Calvet, N., et al. 2004, ApJS, 154, 391

White, D. W., Gerakines, P. A., Cook, A. M., \& Whittet, D. C. B. 2009, ApJS, 180,182

Whittet, D. C. B., Shenoy, S. S., Bergin, E. A., et al. 2007, ApJ, 655, 332

Wilking, B. A., \& Lada, C. J. 1983 ApJ, 274, 698

Wilking, B. A., Lada, C. J., \& Young, E. T. 1989, ApJ, 340, 823

Wilking, B. A., Greene, T. P., Lada, C. J., et al. 1992, ApJ, 397, 520

Yamada, H., \& Person, W. B. 1964, J. Chem. Phys., 41, 2478

Zasowski, G., Kemper, F., Watson D. M., et al. 2009, ApJ, 694, 459

Ziegler, J. F., Biersack, J. P., \& Ziegler, M. D. 2008, The stopping and range of ions in solids (New York: Pergamon Press), see also http: //www . srim. org 